\title{
Apparent diffusion coefficient measurement of the parotid gland parenchyma
}

\author{
Maja Bruvo $^{1 \wedge}$, Faisal Mahmood ${ }^{2,3} \wedge$ \\ ${ }^{1}$ Radiography, Department of Technology, Faculty of Health, University College Copenhagen, Copenhagen, Denmark; ${ }^{2}$ Laboratory of Radiation \\ Physics, Department of Oncology, Odense University Hospital, Odense, Denmark; ${ }^{3}$ Research Unit for Oncology, Department of Clinical Research, \\ University of Southern Denmark, Odense, Denmark
}

Correspondence to: Maja Bruvo. Birkevaenget 6, 4621 Gadstrup, Denmark. Email: majl@kp.dk.

\begin{abstract}
The measurements of apparent diffusion coefficient (ADC) with diffusion weighted magnetic resonance imaging (DW-MRI) is becoming a popular diagnostic and research tool for examination of parotid glands. However, there is little agreement between the reported ADC values of the parotid gland in published literature. In this review 43 studies on ADC measurement of the parotid glands were included. The analyses indicated several possible culprits of the observed ADC discrepancies. For example, DW-MRI examinations under gustatory stimulation gives higher ADC values compared to the unstimulated parotid gland $(\mathrm{P}=0.003)$. The diffusion weighting factors (b-values) can either increase (b-value $<200 \mathrm{~s} / \mathrm{mm}^{2}$ ) or decrease ADC values (b-values $>1,000 \mathrm{~s} / \mathrm{mm}^{2}$ ). The timing of follow-up DW-MRI after radiotherapy (RT) indicates correlation to the found $A D C$ values $\left(\mathrm{R}^{2}=0.39\right)$. Interestingly, the choice of regions of interest (ROI) appears not to affect the measurements of $\mathrm{ADC}(\mathrm{P}=0.75)$. It can be concluded that there is a critical need for standardization of ADC measurement of the parotid glands to allow valid inter-study comparisons and eventually to reach consensus on the use of $\mathrm{ADC}$ as biomarker.
\end{abstract}

Keywords: Diffusion weighted magnetic resonance imaging (DW-MRI); apparent diffusion coefficient; parotid gland parenchyma

Submitted Oct 21, 2020. Accepted for publication Mar 18, 2021.

doi: $10.21037 /$ qims-20-1178

View this article at: http://dx.doi.org/10.21037/qims-20-1178

\section{Introduction}

Diffusion weighted magnetic resonance imaging (DW-MRI) is a popular diagnostic tool in radiology, and in radiotherapy (RT) it is becoming a standard supplementary technique for outlining the extent of the tumor for treatment planning. In research, its potential as a non-invasive biomarker of treatment response is being studied extensively $(1,2)$. DWMRI provides image contrast based on differences in the Brownian diffusion of water molecules within the tissue. The diffusion can in a post-processing step be quantified in terms of the so-called apparent diffusion coefficient (ADC).

In parotid glands, DW-MRI is commonly used in clinical evaluation, for example with information about localization of the tumor within the parotid gland and differentiation of malignancy from benignity (3). It has also been investigated for the diagnosis of xerostomia, Sjögren's syndrome, Kimura disease and other non-neoplastic disorders affecting the parotid glands. More recently (since 2001) there has been a growing interest in using ADC to investigate functional and structural changes in the parotid glands in patients treated with RT for cancer in the head and neck region to diagnose or predict side effects like xerostomia (4-6).

Furthermore, it may be expected that with the recent clinical release of the hybrid MRI linear accelerator (7)

^ ORCID: Maja Bruvo, 0000-0002-9939-6337; Faisal Mahmood, 0000-0002-7270-7967. 
ADC may be studied even more intensively in the coming years in different anatomies including the parotid gland.

A quick search of the published studies revealed that there is a substantial variation in the study designs, DWMRI acquisition protocols and post processing steps, including definition of the region of interest (ROI) and $\mathrm{ADC}$ calculation methods. This is problematic since there is a potential risk that the reported $\mathrm{ADC}$ values are correlated to technical differences of the studies rather than biological differences within patient subgroups. This has in fact been indicated in a few previous studies of for example DW-MRI protocols (8), ROI definition (9), and timing of DW-MRI following gustatory stimulation and RT $(5,10)$.

The lack of standardization of ADC measurement in the parotid gland is a potential limitation for valid inter-study comparison, and in the end to reach valid clinical consensus for the use of ADC as a biomarker. This review includes all currently published DW-MRI studies where ADC has been used for evaluation of parotid glands, to provide a comprehensive overview of the potential covariates. It is organized into introductory sections about DW-MRI and the parotid gland including an overview of radiation toxicity and ROI selection. This is followed by a discussion of possible factors affecting the ADC of the parotid gland based on the reviewed publications.

Throughout this review the term normal parotid parenchyma is used to designate the disease-free parotid parenchyma. Studies examining normal parotid parenchyma and irradiated normal parotid parenchyma in head and neck cancer patients treated with RT are included to discuss the ADC values in relation to trial design, DWIMRI acquisition and post processing. Studies examining the diseased parotid gland (parotid tumors, Sjögren's syndrome and Kimura disease) are included to survey acquisition parameters only. Conclusions based on current studies and recommendations for future studies are provided.

\section{Technical introduction}

\section{The biophysical basis of DW-MRI}

In DW-MRI, the MRI signal is sensitized to the diffusion of water (hydrogen nuclei) within the tissue. Free diffusion is characterized by a Gaussian displacement distribution, the width of which at a given temperature is proportional to the diffusion coefficient and the time during which diffusion has taken place (diffusion time), i.e., in this framework, the diffusion coefficient can be defined as the proportionality constant between the mean squared displacement of a particle and the time allowed for diffusion. At body temperature $\left(310.15 \mathrm{~K}\right.$ or $\left.37^{\circ} \mathrm{C}\right)$ and at typical diffusions times ( $\sim 5 \mathrm{~ms})$ of the DWI-MRI sequence the mean squared displacement of free water (within an imaging voxel) is about 10 micrometers, the order of magnitude of a human cell. In the tissue the cellular environment delimits the degree of free diffusion, and therefore a structural change in the cellular environment (for example due to pathology) may result in an altered displacement distribution and reflected in the diffusion coefficient. The term apparent diffusion coefficient (ADC) was coined for DW-MRI to underline that it reflects the average diffusivity of water in a heterogeneous cellular environment.

\section{DW-MRI acquisition}

In DW-MRI the challenge is to measure very small and short-lived signals. That requires speed and repetition. The initial development of DW-MRI was done specifically in the subfield of neuroimaging, and focusing the technique on other parts of the body and relevant clinical issues has seen challenges from physiological aspects, such as movement, and anatomical differentiation, posting sudden changes in the signal from tissues or indeed voids, all leading to problems in acquiring the signal and assigning it properly. The increase in field strength in clinically available scanners, moving typically from 1.5 tesla $(\mathrm{T})$ to 3 T, yields an immediate boost in neuroimaging, but often presents a less straightforward advantage in other parts of the anatomy, as not only the signal is increased, but also the attendant artifacts.

In the case of parotid imaging, the initial approach has been to apply the readily available neuroimaging techniques without much alteration. As new hardware, such as specialized coils, and imaging sequences less prone to artifacts have become available, an approach tailored to the specific organ is beginning to appear. In coil design, proximity to the tissue is key, and moving from head coils, designed primarily for brain imaging, to dedicated head and neck $(\mathrm{HN})$ or neurovascular (NV) coils has been a step forward. A shift away from the standard clinical acquisition protocol of two b-values towards an investigation of whether other values would be more appropriate is also beginning to appear.

The DW-MRI sequence consists of a diffusion sensitization part, in which the diffusion gradients are applied, and an imaging part where imaging gradients are applied. Diffusion sensitization is achieved by the key physical concept that magnetic gradients accumulate a 


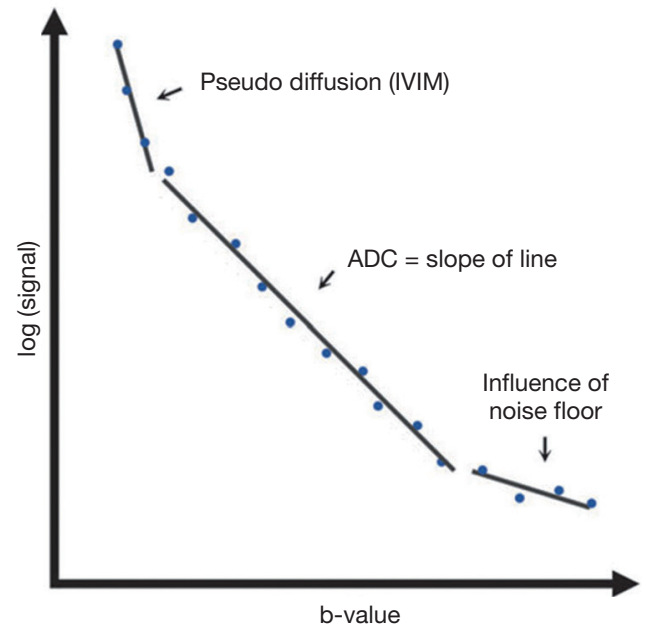

Figure 1 Diagram showing how apparent diffusion coefficient (ADC) is related to the MRI signal at different b-values. Modified from Mahmood and Hansen, 2015 (15). In the low b-values region the signal from capillary blood flow contributes to the total signal. In the high b-value region the noise floor can constrain the recorded signal to stay higher than can be attributed to the underlying diffusion process. ADC should be measured from midrange b-values.

phase difference in water hydrogen nuclei (protons). In the standard DW-MRI a pair of diffusion gradient pulses is used with a 180 refocusing RF pulse in between (pulsed field gradient spin-echo technique) (11). The first gradient labels the protons by inflicting a certain position dependent phase change. In case of static protons, the second gradient will rewind the phase change completely. Diffusing protons on the other hand will not be phase refocused which will result in a decreased signal. The diffusion sensitized signal decays as a function of the amount of diffusion-weighting applied through the use diffusion sensitizing gradients expressed as b-values. For the imaging part most frequently echo planar imaging (EPI) with fat saturation is used since it is fast. Sometimes, fast spin echo (FSE) is preferred because it is less prone to geometrical distortions (12). This is however at the expense of longer imaging time or lower signal-tonoise (SNR). With longer scan times collateral effects such as motion artifacts can further deteriorate image quality.

The optimal choice of b-values is not clearly defined and depends upon system performance (field strength, gradient strength and slew rate), number of signal averages and the clinical application. The usual range of $b$-values in clinical practice is about $1,000 \mathrm{~s} / \mathrm{mm}^{2}$, usually from 0 to
$1,000 \mathrm{~s} / \mathrm{mm}^{2}$, with some anatomical site dependent variations. The upper limit is basically dictated by the hardware capability of clinical systems. If the b-value is set too high the SNR can decrease too much and introduce a bias (13). At b-values below about $200 \mathrm{~s} / \mathrm{mm}^{2}$ the signal attenuation is sensitive to signal loss from capillary perfusion $(14,15)$ (Figure 1). This can be useful if adequately modelled in the postprocessing step, otherwise a bias towards too high ADC estimates should be expected. User-defined number of excitations of individual b-value images is often used to achieve homoscedasticity and sufficient precision.

\section{ADC calculation}

In the simplest interpretation of ADC, tissue with high cell density will have a low ADC (more hindered diffusion) whereas low cell density (e.g., due to necrosis or extracellular oedema) will have higher ADC (less hindered diffusion). This implies that DW-MRI quantifies predominantly diffusion taking place in the extracellular space $(16,17)$. DW-MRI can also provide additional information about tissue microstructure, especially about cell count (18).

To calculate the ADC at least two b-values are required. In a clinical setting the ADC is almost exclusively calculated on the MRI workstation assuming a mono exponential model (free diffusion in a single compartment):

$$
\mathrm{ADC}=\ln (\mathrm{S} 1 / \mathrm{S} 2) /(\mathrm{b} 2-\mathrm{b} 1)
$$

Here, S1 and S2 are the signal values in a single voxel or average signal value of a region of interest at two different b-values, b1 and b2, respectively (11). This shows that the ADC becomes the slope of the line connecting the two points $[\mathrm{b} 1, \ln (\mathrm{S} 1)]$ and $[\mathrm{b} 2, \ln (\mathrm{S} 2)]$. If more b-values (or repetitions of the same b-values) are acquired a better estimate of ADC (the slope) can be achieved. Also, with more b-values (typically 5 or more) within the same b-value range (typically $0-1,000 \mathrm{~s} / \mathrm{mm}^{2}$ ) it is possible to use a model that describes the signal better than the mono exponential model. The bi-exponential intravoxel incoherent motion (IVIM) model (19) is a popular alternative.

Voxel-by-voxel calculation of ADC better appreciates the heterogeneity of the tissue, for example by extracted histogram descriptors (e.g., minimum and maximum $\mathrm{ADC}$ ). On the other hand, by averaging the signal within a given ROI before calculating the ADC is an approach less sensitive to bulk motion. The choice of analyses may depend on the quality of the DW-MRI scans available, and 
in general, it is not clear which of these two approaches should be used in clinical investigations.

\section{Physiology of parotid glands}

The parotid glands are the largest salivary glands located in the retromandibular fossa. They are purely serous glands containing an abundant amount of adipose tissue that occupies about a half of the gland parenchyma. The parotid glands are secretory organs, where various molecules are conveyed into the saliva-producing cells (acinar cells) via the capillary network, and the saliva is moving in the small ductal termination surrounded by acinar cells and is then secreted into the lumen of the excretory ductal system (20). These movements of molecules and water represent the main function of the parotid glands.

Human unstimulated salivary flow rates display circadian variation that is a cyclic event controlled by the body's biological clock, with a peak level in the afternoon and a time span of 12 hours between highest and lowest secretory rates $(21,22)$. The parotid gland mainly secretes saliva in stimulated conditions like chewing, when it secretes $50-60 \%$ of total whole mouth saliva $(23,24)$. Within the gland, alterations in blood perfusion also occur in response to various stimuli. Therefore, such a process is altered in the diseased states of the parotid glands, for example, in sialoadenitis and Sjögren's syndrome.

\section{Irradiation and parotid glands}

Parotid and other salivary glands are highly sensitive to ionizing radiation, which can lead to irreversible loss of gland function, xerostomia and reduced quality of life in patients after RT (25). Mechanisms of radiation-induced damage of salivary glands have previously been investigated, suggesting selective damage of plasma membrane of the secretory cells immediately after radiation exposure, followed by damage of DNA, death of acinar progenitor cells and finally lysis of acinar cells $(26,27)$. Loss of acinar cells and glandular shrinkage occurs during the acute phase, 0-10 days after radiation exposure (28). Affected individuals display a $50-60 \%$ loss of salivary flow in this first week of RT $(25,29)$. The chronic effects of radiation (more than 240 days after radiation exposure) may be the consequence of acute damage to salivary glands (30). Chronically, affected individuals continue to display significant decreases in salivary flow and are diagnosed with xerostomia for several months or years following RT $(25,29,30)$. Patients receiving low dose ( $<25$ Gy mean dose) to their salivary glands can experience recovery of salivary function within $12-24$ months $(25,30,31)$. A mean dose above 39 Gy to the parotid gland inflicts high risk of irreversible damage of parotid gland tissue and permanent xerostomia (32).

\section{Regions of interest (ROI) in parotid glands}

In the parotid glands, ROIs are usually manually drawn, as a reader-based circular ROIs or as an outline of as much of the gland parenchyma as possible, excluding the regions containing large vessels such as the retromandibular vein and external carotid artery. Each method has its intrinsic advantages and disadvantages. Reader-based circular ROI on selected slices may lead to inter-reader variability during ROI placement and may not reflect tissue heterogeneity. While whole-volume ROI overcomes the above-mentioned problem, it is a time-consuming process, which limits its application in routine clinical practice (9). Mahmood et al. 2015 (33) concluded in a study of brain metastases patients treated with whole brain irradiation that the effect of ROI strategy is significant for the ADC calculation. This indicates that ROI methods should be considered in studies where ADC is used.

\section{The studies}

The literature search was conducted in PubMed and Web of Science databases and resulted in $43 \mathrm{DW}$-MRI studies where ADC has been used for evaluation of parotid glands (Table 1). All studies were written in English and published from 2001 to 2019. They are sorted by their population size, from 4 to 149 study subjects. Additionally, Table 1 contains details regarding scanner manufacturer, acquisition method and ADC calculation. Study 13 (4) uses only b-values below $150 \mathrm{~s} / \mathrm{mm}^{2}$ for calculation of ADC and may therefore be considered an outlier.

\section{Factors affecting measurments of ADC}

\section{ADC of normal parotid parenchyma}

The reported mean ADC values derived from 25 studies reporting ADC values of the normal parotid parenchyma are illustrated in Figure 2. The ADC values for parotid glands range from $0.28 \times 10^{-3}$ to $2.42 \times 10^{-3} \mathrm{~mm}^{2} / \mathrm{s}$.

\section{The effect of gustatory stimulation}

Nine studies are using gustatory stimulation during DWMRI examinations of the normal parotid parenchyma. Since 
Table 1 Included studies with the clinical condition of focus, population size, details about scanner manufacturer, acquisition method and ADC calculation

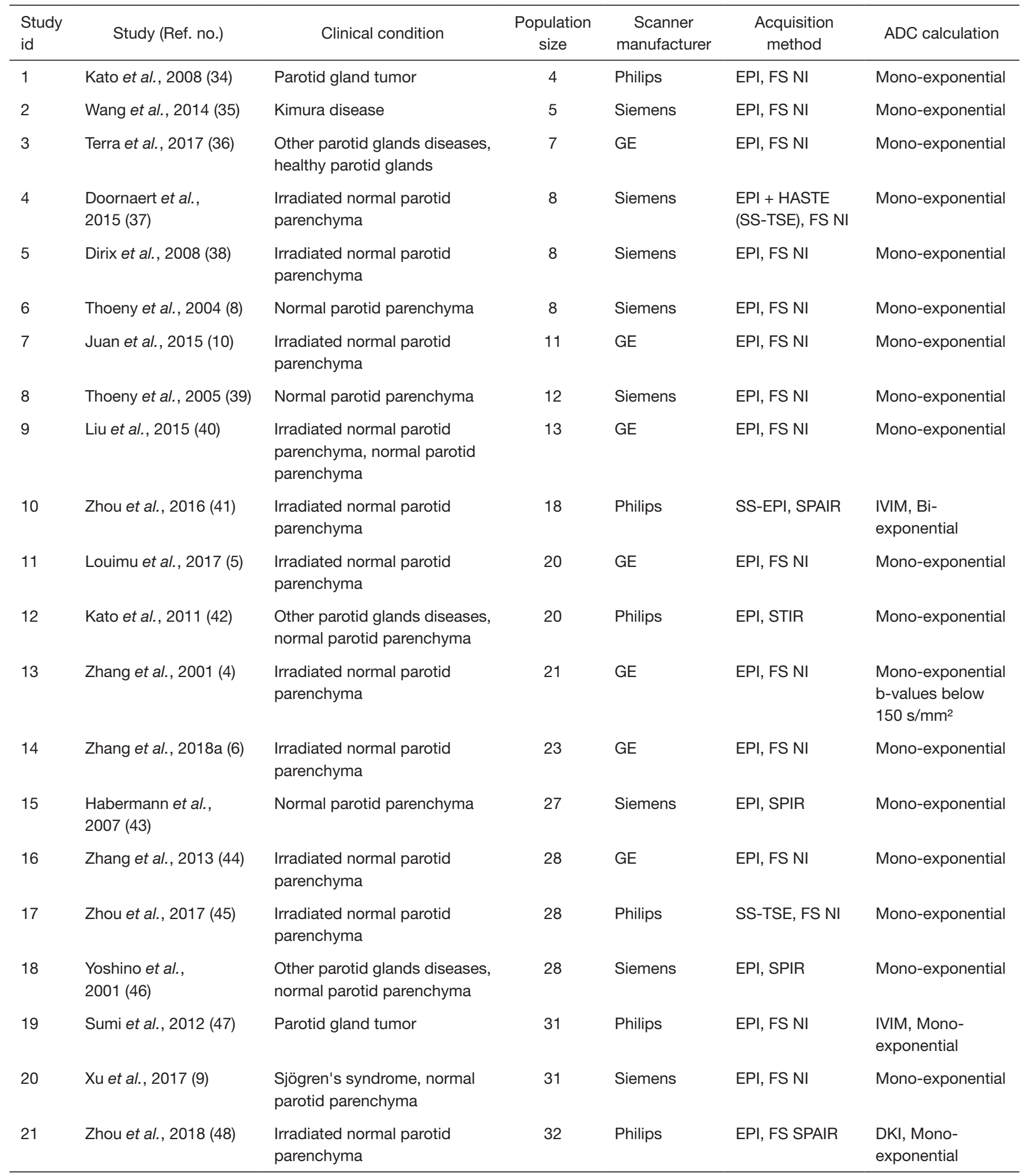

Table 1 (continued) 
Table 1 (continued)

\begin{tabular}{|c|c|c|c|c|c|c|}
\hline $\begin{array}{l}\text { Study } \\
\text { id }\end{array}$ & Study (Ref. no.) & Clinical condition & $\begin{array}{l}\text { Population } \\
\text { size }\end{array}$ & $\begin{array}{c}\text { Scanner } \\
\text { manufacturer }\end{array}$ & $\begin{array}{l}\text { Acquisition } \\
\text { method }\end{array}$ & ADC calculation \\
\hline 22 & $\begin{array}{l}\text { Matsushima et al., } \\
2007 \text { (49) }\end{array}$ & Parotid gland tumor & 32 & $\mathrm{NI}$ & $\mathrm{EPI}, \mathrm{FS} \mathrm{NI}$ & Mono-exponential \\
\hline 23 & Juan et al., 2009 (50) & Normal parotid parenchyma & 33 & GE & $\begin{array}{l}\text { EPI, both FS } \\
\text { and no-FS, NI }\end{array}$ & Mono-exponential \\
\hline 25 & Zhang et al., 2018b (52) & Parotid gland tumor & 36 & Siemens & $\mathrm{EPI}, \mathrm{FS} \mathrm{NI}$ & Mono-exponential \\
\hline 26 & $\begin{array}{l}\text { Matsusue et al., } \\
2017 \text { (53) }\end{array}$ & Parotid gland tumor & 36 & GE & $\mathrm{EPI}, \mathrm{FS} \mathrm{NI}$ & Mono-exponential \\
\hline 27 & Ikeda et al., 2004 (54) & Parotid gland tumor & 36 & GE & $\mathrm{EPI}, \mathrm{FS} \mathrm{NI}$ & Mono-exponential \\
\hline 29 & Eida et al., 2007 (56) & $\begin{array}{l}\text { Parotid gland tumor, normal } \\
\text { parotid parenchyma }\end{array}$ & 41 & Philips & EPI, FS NI & Mono-exponential \\
\hline 30 & Kato et al., 2017 (57) & Parotid gland tumor & 45 & Philips & EPI, FS STIR & Mono-exponential \\
\hline 31 & Milad et al., 2017 (58) & Parotid gland tumor & 46 & Philips & $\mathrm{EPI}, \mathrm{FS} \mathrm{NI}$ & Mono-exponential \\
\hline 32 & $\begin{array}{l}\text { Motoori et al., } \\
2004 \text { (59) }\end{array}$ & $\begin{array}{l}\text { Other parotid glands diseases, } \\
\text { parotid gland tumor }\end{array}$ & 46 & GE & EPI, FS NI & Mono-exponential \\
\hline 33 & $\begin{array}{l}\text { Yabuuchi et al., } \\
2008(60)\end{array}$ & Parotid gland tumor & 47 & Siemens & $\mathrm{EPI}, \mathrm{FS} \mathrm{NI}$ & Mono-exponential \\
\hline 34 & Zhang et al., 2018c (61) & Parotid gland tumor & 51 & Siemens & $\mathrm{EPI}, \mathrm{FS} \mathrm{NI}$ & Mono-exponential \\
\hline 38 & Sun et al., 2019 (65) & $\begin{array}{l}\text { Parotid gland tumor, normal } \\
\text { parotid parenchyma }\end{array}$ & 65 & Philips & EPI, TSS, FS NI & Mono-exponential \\
\hline 39 & Ries et al., 2008 (66) & $\begin{array}{l}\text { Other parotid glands diseases, } \\
\text { normal parotid parenchyma }\end{array}$ & 71 & Siemens & EPI, FS SPIR & Mono-exponential \\
\hline 40 & Celebi et al., 2013 (67) & Other parotid glands diseases & 75 & GE & EPI, FS STIR & Mono-exponential \\
\hline 41 & Wang et al., 2001 (68) & Parotid gland tumor & 97 & Siemens & $\mathrm{EPI}, \mathrm{FS} \mathrm{NI}$ & Mono-exponential \\
\hline 42 & Chang et al., 2014 (69) & Normal parotid parenchyma & 100 & GE & $\begin{array}{l}\text { EPI, both FS } \\
\text { and no-FS, NI }\end{array}$ & Mono-exponential \\
\hline 43 & $\begin{array}{l}\text { Habermann et al., } \\
2009(70)\end{array}$ & Parotid gland tumor & 149 & Siemens & EPI, FS SPAIR & Mono-exponential \\
\hline
\end{tabular}

Philips, Philips Medical Systems, Best, Netherlands; Siemens, Siemens Medical Systems, Erlangen, Germany; GE, General Electric medical Systems, Milwaukee, WI, USA; EPI, echo planar imaging; HASTE, half-fourier acquisition single-shot turbo spin-echo; IVIM, intravoxel incoherent motion; DKI, diffusion kurtosis imaging; SPAIR, spectral pre-saturation attenuated inversion recovery; STIR, short-tau inversion recovery; SS, single-shot; TSE, turbo spin-echo; TSS, transversal single-shot; FS, fat-suppression; NI, type not indicated. 


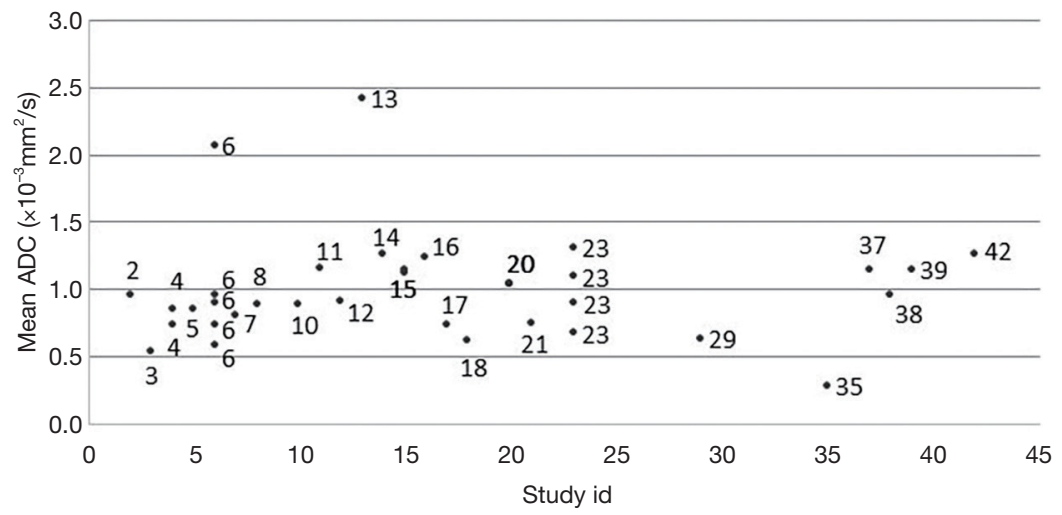

Figure 2 Mean apparent diffusion coefficient (ADC) of normal parotid parenchyma. Numbers indicate study id.

Table 2 Studies using gustatory stimulation under DW-MRI scans

\begin{tabular}{lll}
\hline Study id & \multicolumn{1}{c}{ Stimulating agent } & \multicolumn{1}{c}{ DWI acquisition } \\
\hline 5 & One 500-mg tablet of ascorbic acid & Repeated 8 times with intervals of $30 \mathrm{~s}$ \\
8 & One $500-\mathrm{mg}$ tablet of ascorbic acid & Continuous series without time interval between them (range, 24-28 min) \\
11 & Two $500-\mathrm{mg}$ tablet of ascorbic acid & Repeated 10 times \\
12 & $5 \mathrm{~mL}$ of a commercially available lemon juice & Repeated 9 times without a time interval \\
14 & Six $100 \mathrm{mg}$ tablets of ascorbic acid & Repeated 7 times with intervals of $18 \mathrm{~s}$ \\
15 & $5 \mathrm{~mL}$ of a commercially available lemon juice & 30 seconds after stimulation, the DW sequence was repeated \\
16 & Six $100 \mathrm{mg}$ tablets of ascorbic acid & Repeated 7 times with intervals of $18 \mathrm{~s}$ \\
37 & $5 \mathrm{~mL}$ of a commercially available lemon juice & 30 seconds after stimulation, the DW sequence was repeated \\
39 & $5 \mathrm{~mL}$ of a commercially available lemon juice & 30 seconds after stimulation, the DW sequence was repeated
\end{tabular}

the parotid glands produce only about one-thirds of the total saliva at rest and about two-thirds of the total saliva during gustatory stimulation, more valuable information regarding secretory function of parotid glands can be acquired by DW-MRI during gustatory stimulation $(39,44)$. The nine studies using gustatory stimulation during DWMRI examinations are listed in Table 2 together with the stimulating agent applied during the stimulation. The mean ADC values from those nine studies vary from $0.92 \times 10^{-3}$ to $1.49 \times 10^{-3} \mathrm{~mm}^{2} / \mathrm{s}$ (Figure 3).

All the studies where parotid glands were scanned both at rest and under gustatory stimulation observed a significant increase in ADC values after stimulation (at rest, $1.08 \pm 1.14 \times 10^{-3} \mathrm{~mm}^{2} / \mathrm{s}$, stimulated, $1.22 \pm 1.19 \times 10^{-3} \mathrm{~mm}^{2} / \mathrm{s}$, matched pairs t-test (Excel 2019, ver. 16.0, Microsoft Corporation, Washington, USA), $\mathrm{P}=0.003$ (Figure 4), but the pattern of response to gustatory stimulation and the stimulating agent used varied considerably. In the studies
5 and 8 a $500 \mathrm{mg}$ tablet of ascorbic acid was used as the stimulating agent. The patients were advised to let the tablet dissolve in their mouths, not to chew on it. This resulted in an initial decrease and subsequent increase in the ADC values. On the other hand, studies 15, 30 and 39, having used lemon juice as a stimulant, and 11, 14, and 16, who performed the gustatory stimulation with six tablets and two instantly bitten tablets of $100 \mathrm{mg}$ of ascorbic acid, reported an initial increase and subsequent fluctuation in the ADC values. This may be explained by the quicker saliva production as a response to more immediate stimulation such as lemon juice, higher number of tablets or instantly bitten tablets of ascorbic acid are likely to stimulate simultaneously more receptors than a single slowly dissolving tablet of ascorbic acid does.

There are also differences in when and how frequent DW-MRI were acquired during gustatory stimulation (Table 2). Some of the studies (Study id: 15, 37, 39) 


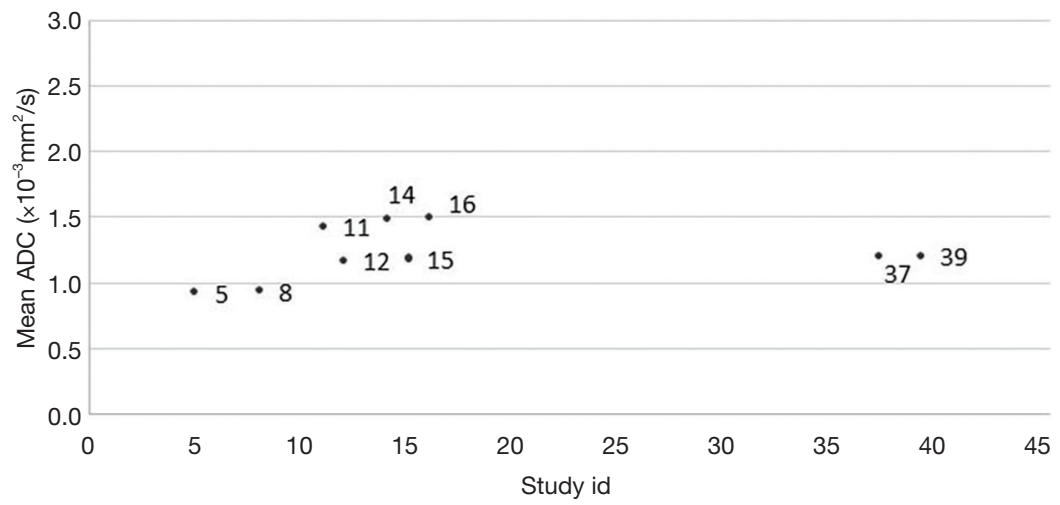

Figure 3 Mean apparent diffusion coefficient (ADC) of normal parotid parenchyma under gustatory stimulation. Numbers indicate study id.

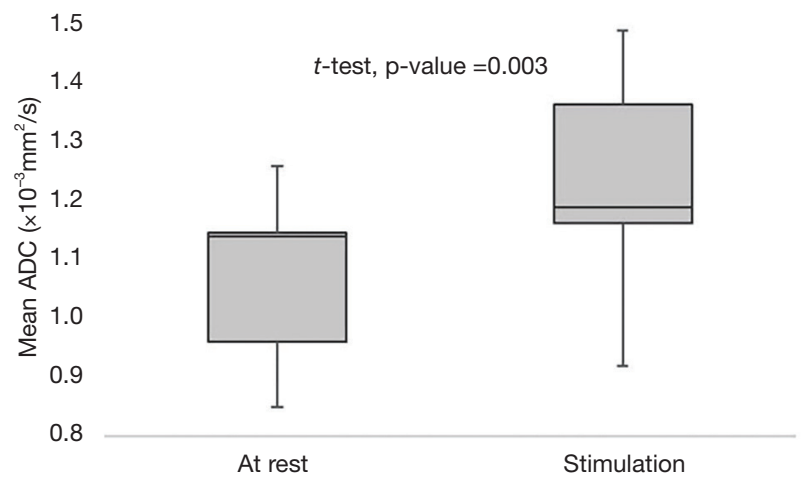

Figure 4 Mean apparent diffusion coefficient (ADC) of parotid glands from nine studies using gustatory stimulation under DWIMR examinations, first at rest and then under stimulation. T-testMatched pairs $t$-test.

performed only one DW-MRI scanning 30 seconds after stimulation, while the others repeated the sequence 7-10 times during stimulation (Study id: 5, 8, 11, 12, $14,16)$. There seems to be no difference in mean ADC values between these two groups of studies (One DWMRI scanning 30 seconds after stimulation, three studies, mean $\mathrm{ADC}=1.19 \pm 0.02 \times 10^{-3} \mathrm{~mm}^{2} / \mathrm{s}$; Repeated sequence 7-10 times during stimulation, six studies, mean ADC $=1.29 \pm 0.27 \times 10^{-3} \mathrm{~mm}^{2} / \mathrm{s}$ ).

\section{The effect of b-values}

Figure 5 shows the distribution of b-values used for ADC measurement in the 43 studies included in this review.

The most frequent individual choices are $\mathrm{b}=0 \mathrm{~s} / \mathrm{mm}^{2}$ and $\mathrm{b}=1,000 \mathrm{~s} / \mathrm{mm}^{2}$ (Figure 6), and the combination of these two which is present in $33 \%$ of the studies. The use of $\mathrm{b}=500 \mathrm{~s} / \mathrm{mm}^{2}$ in combination with $\mathrm{b}=0 \mathrm{~s} / \mathrm{mm}^{2}$ and $\mathrm{b}=1,000 \mathrm{~s} / \mathrm{mm}^{2}$ is reported in 11 studies $(24 \%)$. The overall most frequent range is $b=0 \mathrm{~s} / \mathrm{mm}^{2}$ to $b=1,000 \mathrm{~s} / \mathrm{mm}^{2}$ which is reported in $60 \%$ of the studies. Furthermore, only three studies exceed $b=1,000 \mathrm{~s} / \mathrm{mm}^{2}$ (Study id: 3, 18, 21), of which one extended to $b=2,000 \mathrm{~s} / \mathrm{mm}^{2}$ (Study id: 21). In the latter study a higher field strength ( $3 \mathrm{~T}$ ) was used compared to the other two studies $(1.5 \mathrm{~T})$, which might explain the choice of the much higher b-value (diffusional kurtosis was also reported which also requires high b-values). Multiple b-values $(b>3)$ are used in 11 studies, 5 of which acquire most of their $b$-values up till $b=300 \mathrm{~s} / \mathrm{mm}^{2}$. Six studies avoid the use of low b-values (Study id: 3, 5, 8, 29, 31, 35).

The b-value profiles shown here (Figure 5) reflects that the typical radiology DWI-MRI protocol is acquired with two b-values only, a high b-value, typically 800 or $1,000 \mathrm{~s} / \mathrm{mm}^{2}$, and $0 \mathrm{~s} / \mathrm{mm}^{2}$ (i.e., without diffusion weighting).

In the high end of the b-value range (typically above $1,000 \mathrm{~s} / \mathrm{mm}^{2}$ for most clinical systems), there is a risk that the measurement has very low SNR. For this reason, it is advised to assess the SNR at the highest b-value planned for the study with the intended coil setup. A generally valid way of increasing the SNR is by increasing the number of signals averaged. This however does not remove the bias from the measurement if the initial SNR is too low (13) and results in an underestimated ADC value if not properly dealt with in the post-processing step (71).

For the examination of the effect of choice of different b-values on ADC measurements of normal parotid parenchyma 25 studies are selected. Figure 7 shows how the choice of different b-values affect calculation of ADC. It is seen that if only low b-values are used $\left(<300 \mathrm{~s} / \mathrm{mm}^{2}\right)$, like in study 13, it will lead to higher ADC values. This was in particular demonstrated in study 6 , study of 


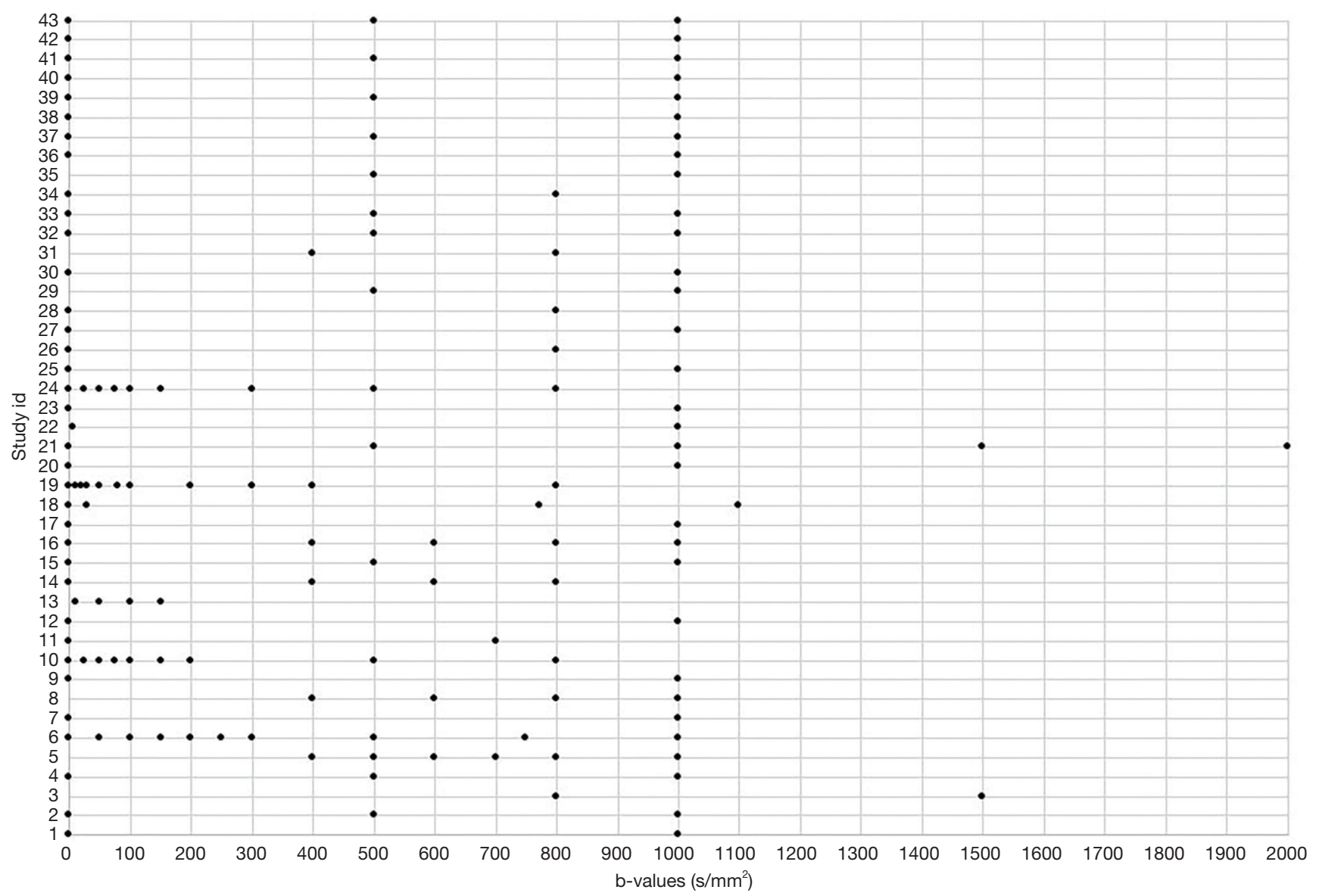

Figure 5 Overview of the variation in b-values in all 43 included studies.

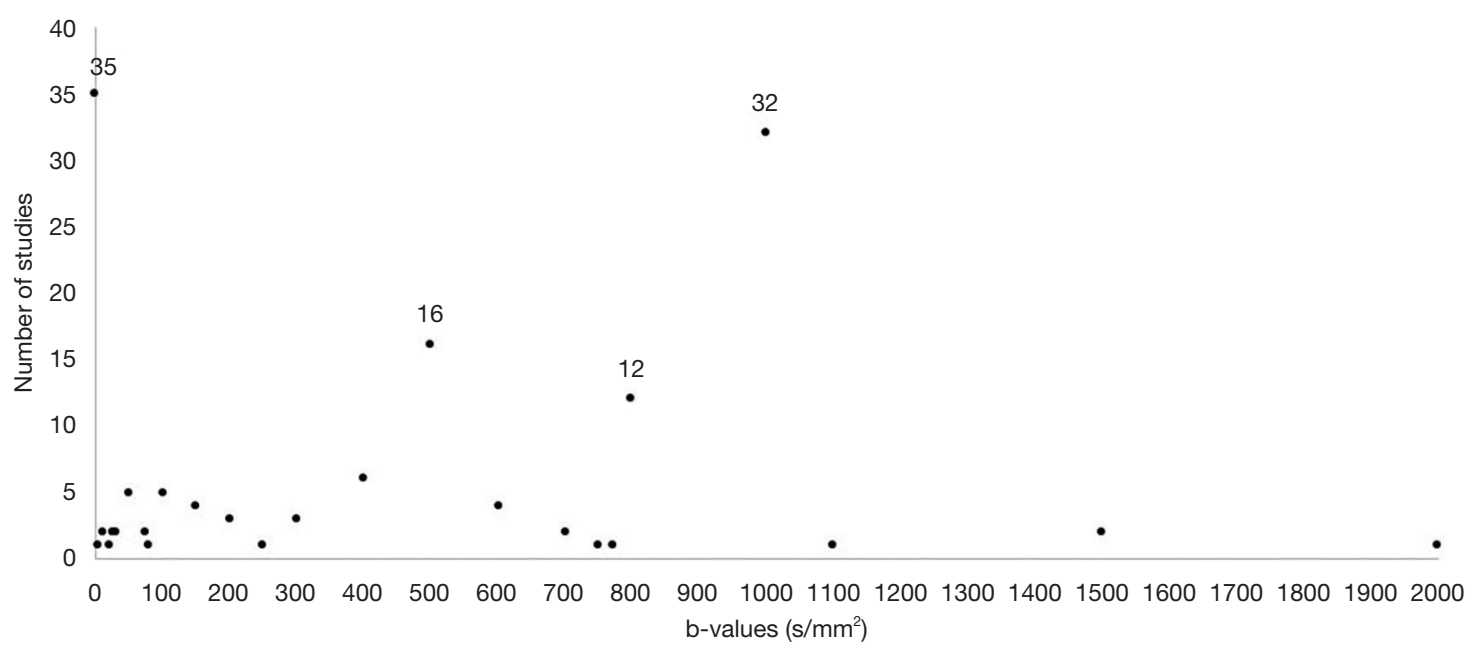

Figure 6 The distribution of reported b-values. The most popular individual choices of b-values: $\mathrm{b}=0 \mathrm{~s} / \mathrm{mm}^{2}(35 \mathrm{studies}), \mathrm{b}=500 \mathrm{~s} / \mathrm{mm}^{2}(16$ studies), $\mathrm{b}=800 \mathrm{~s} / \mathrm{mm}^{2}$ (12 studies), $\mathrm{b}=1,000 \mathrm{~s} / \mathrm{mm}^{2}$ (32 studies). 


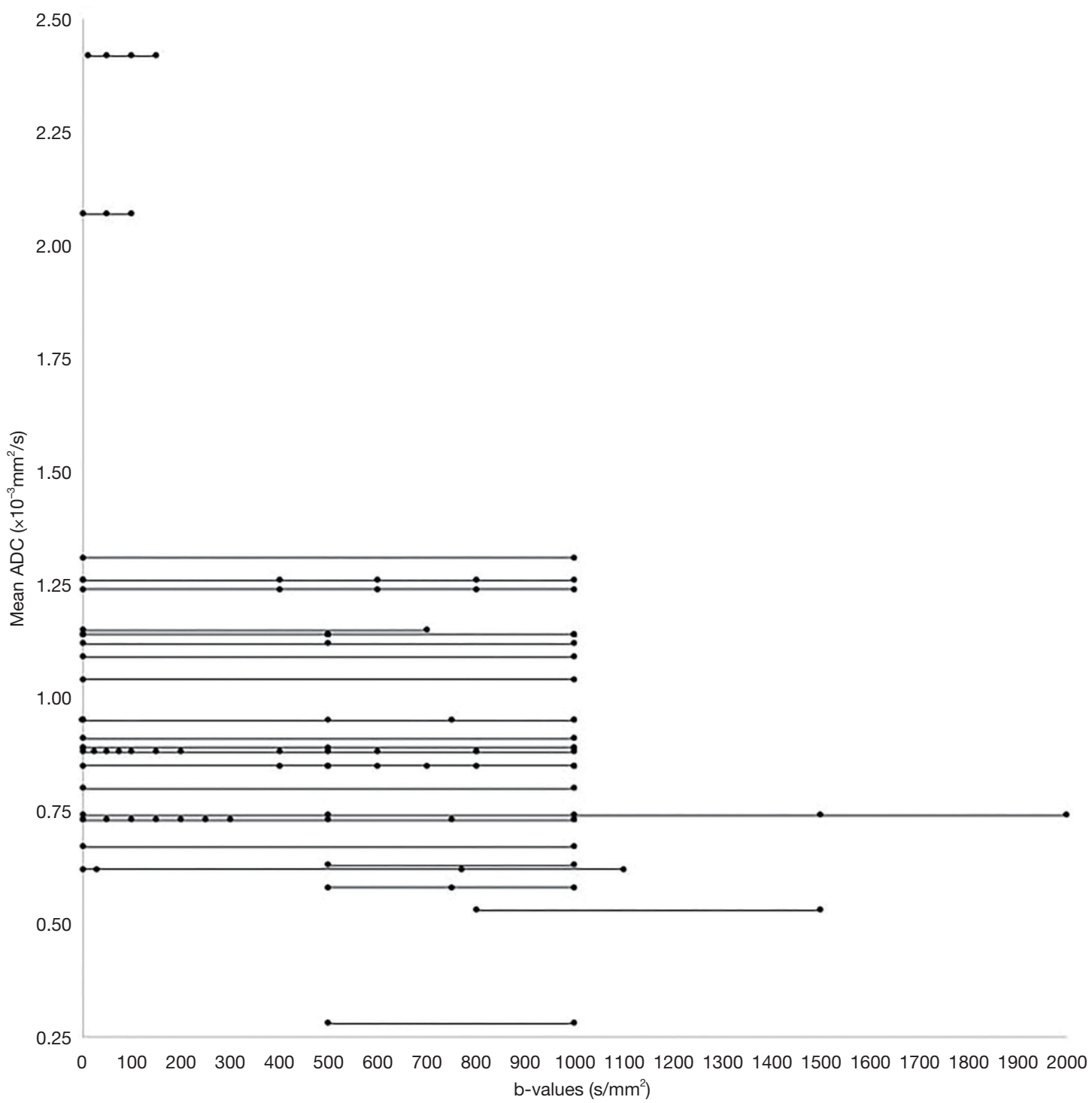

Figure 7 Reported mean apparent diffusion coefficient (ADC) values of the normal parotid parenchyma and the corresponding b-values configurations. Horizontal lines indicate that b-values belong to the same acquisition.

the influence on b-values on the ADC of the parotid gland. When lower b-values were included in a monoexponential model higher ADC was obtained. This increase in ADC is related to the signal contribution of the socalled IVIM which stems from capillary perfusion (14). This means that if two exponentials are required to model data properly, and if the ADC is calculated from all acquired b-values using a mono exponential model, it will be overestimated (72). Studies 10 and 19 acquired DWMRI with both lower and higher b-values but accounted for capillary perfusion with the IVIM formalism and arrived at lower ADC values. In the other hand, the use of high $\mathrm{b}$-values in absence of $\mathrm{b}=0 \mathrm{~s} / \mathrm{mm}^{2}$ will lead to low ADC values. This is also indicated in this overview where six studies avoided use of low b-values (Figure 7).

\section{The effect of ROI definition method}

From the examined literature, region of interest (ROI) selection methods can be divided into four groups: wholegland ROI, ROI on the slice with largest parotid gland cross section, ROI selected on 3 contiguous slices, and readerbased circular ROI in selected slices (Figure 8). 

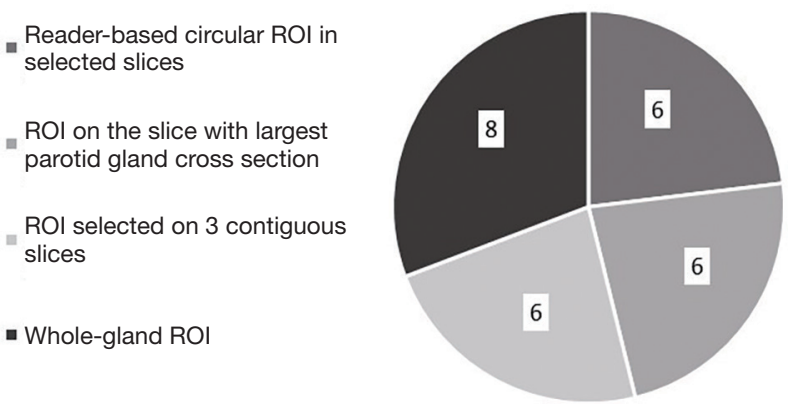

Figure 8 Number of studies divided into the different delineation strategies.

Table 3 shows an overview of ROI selection methods in the 25 studies describing delineation of normal parotid parenchyma. There is no significant difference in mean $\mathrm{ADC}$ values between the four ROI selection methods (reader-based circular ROI in selected slices, mean $\mathrm{ADC}=1.08 \pm 0.60 \times 10^{-3} \mathrm{~mm}^{2} / \mathrm{s}$, whole-gland ROI, mean $\mathrm{ADC}=0.90 \pm 0.30 \times 10^{-3} \mathrm{~mm}^{2} / \mathrm{s}$, ROI on the slice with largest parotid gland cross section, mean $\mathrm{ADC}=$ $0.93 \pm 0.18 \times 10^{-3} \mathrm{~mm}^{2} / \mathrm{s}$, ROI selected on 3 contiguous slices, mean $\mathrm{ADC}=1.06 \pm 0.26 \times 10^{-3} \mathrm{~mm}^{2} / \mathrm{s}$, The one-way analysis of variance (ANOVA) (Excel 2019, ver. 16.0, Microsoft Corporation, Washington, USA, $\mathrm{P}=0.75$ ).

Study 20 performed ROC analysis based on whole-gland ROI, selected slice ROI on the largest slice and readerbased circular ROI. This analysis relived no significant difference in ADC values between the three ROI selection methods. On the other hand, the same study showed that the best inter- and intra-reader agreement during ROI placement, and the best diagnostic ability in detecting parotid gland abnormality was achieved using whole-gland ROI method. The study pointed out that whole-gland ROI method is significantly more time consuming which might be a distinct obstacle to its routine application in clinical practice. In contrast, it points out that the selected slice ROI approach significantly reduce the delineation time while showing comparable diagnostic performance and is recommended for routine clinical practice. Reader-based circular ROI was not recommended because of the relatively lower inter-reader agreement and diagnostic performance.

Study 38 performed ADC measurements with defined 12 concentric round ROIs (areas: 9, 28, 34, 50, 60, 82, 93, 98, $115,130,136$, and $149 \mathrm{~mm}^{2}$ ). This study revealed that there were no significant differences in mean ADCs with the 12 ROIs for normal parotid parenchyma.
Table 3 ROI definition methods from 25 studies describing delineation of normal parotid parenchyma

\begin{tabular}{|c|c|}
\hline Study id & ROI definition method \\
\hline 4 & Reader-based circular ROI: Three $7 \mathrm{~mm}$ ROls \\
\hline 5 & Whole-gland ROI \\
\hline 6 & Reader-based circular ROI: One ROI \\
\hline 7 & Selected slice ROI on the largest slice \\
\hline 8 & Whole-gland ROI \\
\hline 9 & Whole-gland ROI \\
\hline 10 & Selected slice ROI on the largest slice \\
\hline 11 & Whole-gland ROI \\
\hline 12 & Selected slice ROI on the largest slice \\
\hline 13 & $\begin{array}{l}\text { Reader-based circular ROI: One } 9.4 \mathrm{~mm} \text { ROI on } 4 \\
\text { DWI images }\end{array}$ \\
\hline 14 & Selected slice ROI on 3 contiguous slices \\
\hline 15 & Selected slice ROI on the largest slice \\
\hline 16 & Selected slice ROI on 3 contiguous slices \\
\hline 17 & Whole-gland ROI \\
\hline 18 & $\begin{array}{l}\text { Reader-based circular ROI: } 3-4,100-200 \text { pixels } \\
\text { ROls }\end{array}$ \\
\hline 20 & $\begin{array}{l}\text { Whole-gland ROI; Selected slice ROI on the largest } \\
\text { slice; Reader-based } 3 \text { circular ROI }\end{array}$ \\
\hline 21 & Selected slice ROI on 3 contiguous slices \\
\hline 23 & Selected slice ROI on 3 contiguous slices \\
\hline 24 & Selected slice ROI on 3 contiguous slices \\
\hline 29 & Selected slice ROI on the largest slice \\
\hline 35 & Whole-gland ROI \\
\hline 37 & Whole-gland ROI \\
\hline 38 & $\begin{array}{l}\text { Reader-based circular ROI: } 12 \text { concentric round } \\
\text { ROls }\end{array}$ \\
\hline 39 & Whole-gland ROI \\
\hline 42 & Selected slice ROI on 3 contiguous slices \\
\hline
\end{tabular}

$\mathrm{ROI}$, region of interest.

\section{Irradiated normal parotid parenchyma}

For the examination of the effect of irradiation on ADC measurements of normal parotid parenchyma 10 studies that report both mean dose to the parotid glands and mean ADC values are selected (Study id: 4, 5, 7, 10, 11, 13, 14, 16, $17,21)$. Study 13 , using only low b-values, which therefore 


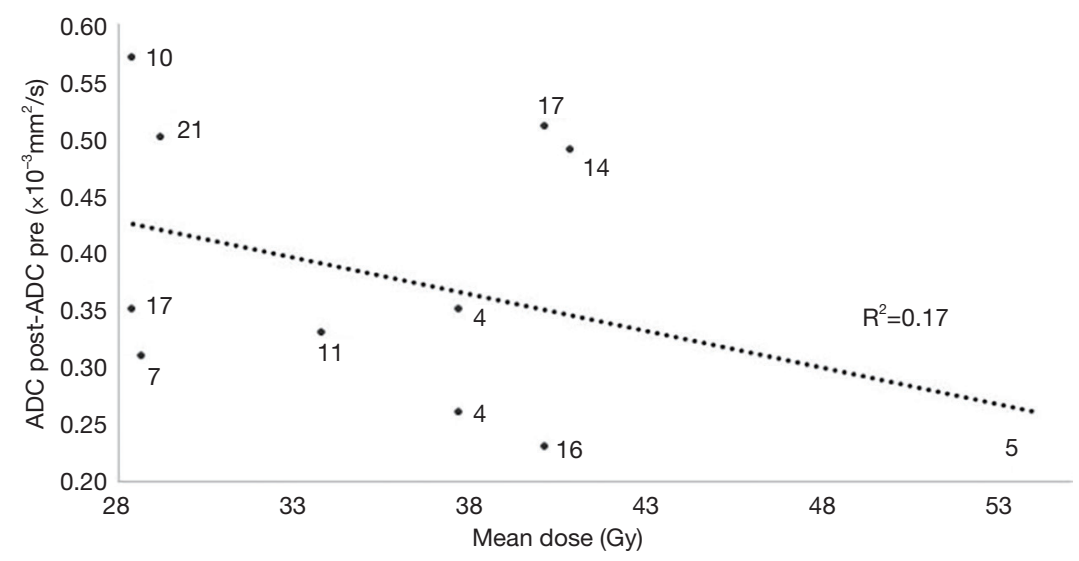

Figure 9 The change in apparent diffusion coefficient (ADC) from pre-RT to post-RT as a function of mean dose (28.4-53.9 Gy). R ${ }^{2}$ correlation coefficient. Numbers indicate study id.

more likely is a measure of so-called pseudo diffusion from perfusion and saliva flow, rather than true diffusion, was also excluded, leaving nine studies to be examined.

\section{The effect of radiation dose}

There is a significant difference between pre-RT ADC and post-RT ADC values based on the nine studies examined (pre-RT, mean $\mathrm{ADC}=0.92 \pm 0.21 \times 10^{-3} \mathrm{~mm}^{2} / \mathrm{s}$, post-RT, mean $\mathrm{ADC}=1.31 \pm 0.28 \times 10^{-3} \mathrm{~mm}^{2} / \mathrm{s}$, matched pairs t-test (Excel 2019, ver. 16.0, Microsoft Corporation, Washington, USA), $\mathrm{P}<0.001)$. The changes in mean ADC values were all positive, i.e., post RT ADC were higher than pre-RT ADC. A very early in-treatment transient reduction in ADC followed by a steady increase can be indicative of good response (73). This can be attributed to cell swelling (cytotoxic edema) followed by necrosis and lysis resulting in reduced cellularity $(1,18)$.

There was a weak correlation between the change in $\mathrm{ADC}$ and the mean dose to the parotid glands $\left(\mathrm{R}^{2}=0.17\right)$ (Figure 9).

The relationship between the mean dose to the salivary glands and changes in ADC in the unstimulated state has been investigated by studies 4, 7, 11, 21 and 24. Study 24 found no significant correlation between ADC changes and mean dose to the parotid glands. Meanwhile, study 4 found a slight correlation $(\mathrm{r}=0.33)$ between mean dose to the salivary glands and changes of ADC at 2 to 3 months after end of the RT course. Study 11 was the first study to confirm a dose-response relationship in ADC changes in a longer term follow up. The increase in $\mathrm{ADC}$ was evident in irradiated salivary glands, and correlated with mean dose (at rest, $\mathrm{r}=0.61, \mathrm{P}<0.001$; under stimulation, $\mathrm{r}=0.48, \mathrm{P}<0.01$ ).
Study 7 found that the parotid gland ADC was positively associated with the radiation dose $\left(\mathrm{R}^{2}=0.212, \mathrm{P}=0.0001\right)$. Study 21 showed no correlation between ADC values and mean radiation dose.

\section{The effect of post radiotherapy timing of DW-MRI}

Post RT treatment timing vary from 7 days (Study id: 14) to 270 days (Study id: 5) in the nine included studies. This wide range in the timing of the DW-MRI can influence changes in mean ADC considerably, since the radiation induced damage of salivary gland is most pronounced in the acute phase (0-10 days) and early phase (10-60 days) after RT dye to loss of acinar cells and glandular shrinkage (28), and after that a partial restitution of parotid gland function can appear during the first two years after RT (74). Therefore, the largest changes in mean ADC values are expected within the first 60 days after end of the RT course (10). This is indeed seen in the reviewed data (Figure 10), as a slight negative correlation between changes in mean ADC pre-post values and time point of post treatment $\left(\mathrm{R}^{2}=0.39\right)$.

Study 7 reported longitudinal evaluation of parotid glands after DWI-MR examinations $51.2 \pm 15.9$ days (time point 1), $240.3 \pm 54.6$ days (time point 2 ), and $489.3 \pm 99.2$ days (time point 3 ) after RT. The ADC post-RT was highest at time point 1 and decreased through time point 2 and 3 . At time point 3, although the ADC post was still higher than pre-RT ADC, the difference was not significant $(\mathrm{P}=0.153)$ while the post-RT ADC was significantly higher at time point $1(\mathrm{P}<0.005)$ and $2(\mathrm{P}<0.005)$ than pre-RT ADC, respectively. Similar results were obtained from study 14 where parotid ADC values showed an increase one week after RT (pre RT, mean ADC $=1.26 \pm 0.10 \times 10^{-3} \mathrm{~mm}^{2} / \mathrm{s}$, 


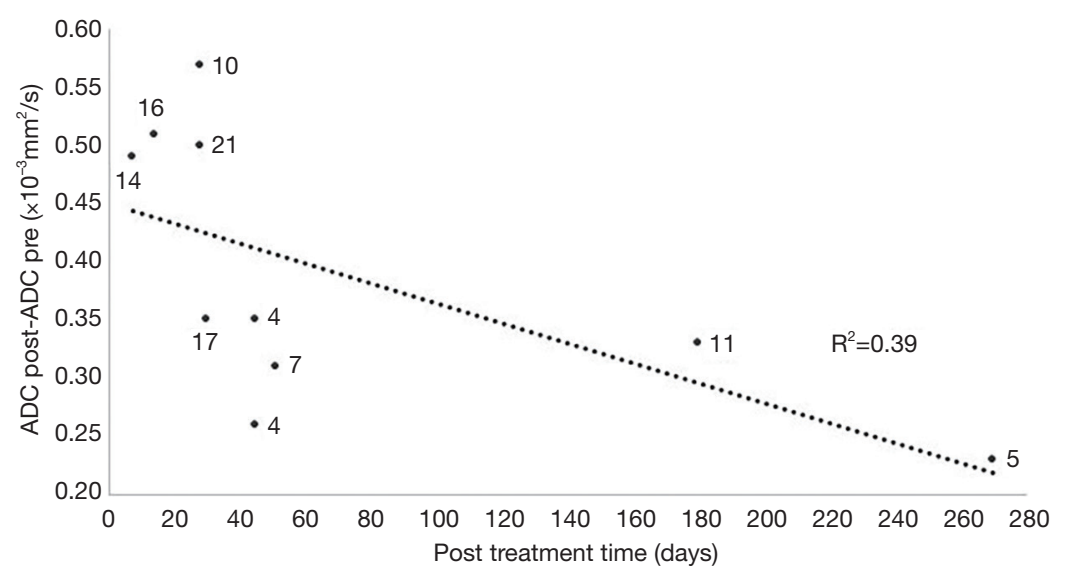

Figure 10 Apparent diffusion coefficient (ADC) change from pre-RT to post-RT plotted as function of post treatment time in days (7-270 days). $\mathrm{R}^{2}$-correlation coefficient. Numbers indicate study id.

one week after $\mathrm{RT}$, mean $\mathrm{ADC}=1.75 \pm 0.16 \times 10^{-3} \mathrm{~mm}^{2} / \mathrm{s}$, $\mathrm{P}<0.001)$, followed by a decrease at one year after $\mathrm{RT}$ (one year post-RT, mean $\mathrm{ADC}=1.57 \pm 0.15 \times 10^{-3} \mathrm{~mm}^{2} / \mathrm{s}$, $\mathrm{P}<0.001)$.

\section{Other factors influencing $A D C$}

During the review process other potential ADC modulating factors were disclosed.

It is known that saliva flow rates display circadian variation $(21,22)$, and thus ADC may show a similar rhythm. Only one study (Study id:16) performed all DW-MRI examinations around the same time of day. In this study patients were also asked not to eat or drink at least one hour prior to examination to secure that parotid glands were at rest at time of the examination. Examinations performed under the same physical conditions and at the same time of day are crucial for reproducibility of examinations (75).

The negative association between parotid ADC of healthy volunteers and age has been shown in previous studies (76). The age-related changes in the parotid glands is therefore another factor that can influence ADC measurements but has not been separately analyzed in any of the included studies.
Different diets and nutritional states by the time of examination, different seasons and temperatures, smokers $v s$. non-smokers, medications, certain medical conditions, and differences in race may also influence the saliva production and therefore changes in the ADC (77-80). Further, there is a high inter-individual variability of saliva production (up to $40-50 \%)$ in healthy volunteers $(80,81)$. This suggests that $\mathrm{ADC}$ variability could be considerable due to this natural difference in parotid function. One way to mitigate this effect is by conducting longitudinal studies to assess the individual changes in ADC allowing for linear mixed effect analyses.

\section{Conclusion}

The review analyses revealed a discrepancy in the reported ADC values of the parotid gland based on 43 clinical studies. The analysis indicates that technical differences related to trial design, MRI acquisition and post-processing can be potential culprits but may not explain all of the variation in measured $\mathrm{ADC}$ values.

Lack of standardization of ADC measurement potentially restricts inter-study comparisons and hampers the effort towards validation of ADC as a biomarker in the parotid gland. Conclusions based on the reviewed studies and 
Table 4 Summary of conclusions and future recommendations

\begin{tabular}{|c|c|c|}
\hline Challenge & Effect & Recommendation \\
\hline $\begin{array}{l}\text { Gustatory } \\
\text { stimulation }\end{array}$ & $\begin{array}{l}\text { Gustatory stimulation increases ADC values } \\
\text { significantly }\end{array}$ & $\begin{array}{l}\text { Stimulating agents like lemon juice, high number of tablets or instantly } \\
\text { bitten tablets of ascorbic acid that gives an immediate stimulation results } \\
\text { in initial increase of ADC values and should be used. If using a stimulating } \\
\text { agent giving an immediate stimulation, it is sufficient to perform only one } \\
\text { DW-MRI scanning } 30 \text { seconds after stimulation }\end{array}$ \\
\hline b-values & $\begin{array}{l}\text { b-values below about } 200 \text { increases ADC. } \\
\text { High b-values carries risk of bias towards } \\
\text { lower ADC }\end{array}$ & $\begin{array}{l}\text { If multiple low b-values are measured in addition to higher b-values a bi- } \\
\text { exponential model should be used, for example IVIM. Alternatively, only } \\
\text { b-values above } 200 \text { should be used with a mono-exponential model. If } \\
\text { very high b-values are used, attention should be given to SNR to avoid } \\
\text { measurement influenced by the noise-floor }\end{array}$ \\
\hline ROI definition & $\begin{array}{l}\text { There is no significant difference in mean } \\
A D C \text { values between the four ROI selection } \\
\text { methods }\end{array}$ & $\begin{array}{l}\text { With no significant difference in mean ADC values between } \mathrm{ROI} \\
\text { selection methods, the only recommendation for choice of ROI selection } \\
\text { method can be given from inter- and intra-reader agreement during ROI } \\
\text { placement. The best inter- and intra-reader agreement can apparently be } \\
\text { achieved using whole gland } \mathrm{ROI} \text { selection methods }\end{array}$ \\
\hline $\begin{array}{l}\text { Irradiation of } \\
\text { parotid glands }\end{array}$ & $\begin{array}{l}\text { The ADC values are showing a significant } \\
\text { increase after irradiation. There is no clear } \\
\text { correlation between ADC changes and } \\
\text { mean dose to the parotid glands. There is a } \\
\text { slight negative correlation between changes } \\
\text { in mean ADC pre-post RT values and time } \\
\text { point of post treatment }\end{array}$ & $\begin{array}{l}\text { Regarding post treatment timing of DW-MRI, it is recommended to } \\
\text { perform it in the acute phase (0-10 days) or early phase (10-60 days) } \\
\text { after RT where the radiation induced damage of salivary glands is most } \\
\text { pronounced and the largest changes in mean ADC values are expected } \\
\text { to occur }\end{array}$ \\
\hline
\end{tabular}

ADC, apparent diffusion coefficient; IVIM, intravoxel incoherent motion; SNR, signal-to-noise; ROI, region of interest.

recommendations for the future studies are listed in Table 4.

\section{Acknowledgments}

The authors wish to acknowledge Dr. Rasmus Hvass Hansen for his ideas on the outline of this review, and for providing writing and language editing assistance.

Funding: None.

\section{Footnote}

Conflicts of Interest: Both authors have completed the ICMJE uniform disclosure form (available at http://dx.doi. org/10.21037/qims-20-1178). The authors have no conflicts of interest to declare.

Ethical Statement: The authors are accountable for all aspects of the work in ensuring that questions related to the accuracy or integrity of any part of the work are appropriately investigated and resolved.

Open Access Statement: This is an Open Access article distributed in accordance with the Creative Commons Attribution-NonCommercial-NoDerivs 4.0 International License (CC BY-NC-ND 4.0), which permits the noncommercial replication and distribution of the article with the strict proviso that no changes or edits are made and the original work is properly cited (including links to both the formal publication through the relevant DOI and the license). See: https://creativecommons.org/licenses/by-nc-nd/4.0/.

\section{References}

1. Koh DM and Collins DJ. Diffusion-weighted MRI in the body: applications and challenges in oncology. AJR Am J Roentgenol 2007;188:1622-35.

2. Mahmood F, Johannesen HH, Geertsen P, Hansen RH. Diffusion MRI outlined viable tumour volume beats GTV in intra-treatment stratification of outcome. Radiother Oncol 2020;144:121-6.

3. Surov A, Meyer HJ, Wienke A. Apparent diffusion coefficient for distinguishing between malignant and benign lesions in the head and neck region: a systematic review and meta-analysis. Front Oncol 2020;9:1362. 
4. Zhang L, Murata Y, Ishida R, Ohashi I, Yoshimura $\mathrm{R}$, Shibuya H. Functional evaluation with intravoxel incoherent motion echo-planar MRI in irradiated salivary glands: a correlative study with salivary gland scintigraphy. J Magn Reson Imaging 2001;14:223-9.

5. Loimu V, Seppälä T, Kapanen M, Tuomikoski L, Nurmi H, Mäkitie A, Tenhunen M, Saarilahti K. Diffusion-weighted magnetic resonance imaging for evaluation of salivary gland function in head and neck cancer patients treated with intensity-modulated radiotherapy. Radiother Oncol 2017;122:178-84.

6. Zhang Y, Ou D, Gu Y, He X, Peng W. Evaluation of salivary gland function using diffusion-weighted magnetic resonance imaging for follow-up of radiation-induced xerostomia. Korean J Radiol 2018;19:758-66.

7. Raaymakers BW, Jürgenliemk-Schulz IM, Bol GH, Glitzner M, Kotte ANTJ, van Asselen B, et al. First patients treated with a $1.5 \mathrm{~T}$ MRI-Linac: Clinical proof of concept of a high-precision, high-field MRI guided radiotherapy treatment. Phys Med Biol 2017;62:L41-L50.

8. Thoeny HC, De Keyzer F, Boesch C, Hermans R. Diffusion-weighted imaging of the parotid gland: Influence of the choice of b-values on the apparent diffusion coefficient value. J Magn Reson Imaging 2004;20:786-790.

9. Xu X, Su G, Hu H, Wang Y, Hong X, Shi H, Wu F. Effects of regions of interest methods on apparent coefficient measurement of the parotid gland in early Sjögren's syndrome at 3 T MRI. Acta Radiol 2017;58:27-33.

10. Juan CJ, Cheng CC, Chiu SC, Jen YM, Liu YJ, Chiu HC, Kao HW, Wang CW, Chung HW, Huang GS, Hsu HH. Temporal Evolution of Parotid Volume and Parotid Apparent Diffusion Coefficient in Nasopharyngeal Carcinoma Patients Treated by Intensity-Modulated Radiotherapy Investigated by Magnetic Resonance Imaging: A Pilot Study. PLoS One 2015;10:e0137073.

11. Stejskal EO and Tanner JE. Spin Diffusion Measurements: Spin Echoes in the Presence of a Time-Dependent Field Gradient. J Chem Phys 1965;42:288-292.

12. Bernstein MA, King KF, Zhou XJ. Handbook of MRI Pulse Sequences. Burlington, MA: Elsevier; 2004.

13. Tofts P, editor. Quantitative MRI of the Brain : Measuring Changes Caused by Disease. Chichester, West Sussex, England: John Wiley \& Sons Ltd;2003.

14. Le Bihan D, Turner R, Macfall JR. Effects of intravoxel incoherent motions (IVIM) in steady-state free precession (SSFP) imaging: application to molecular diffusion imaging. Magn Reson Med 1989;10:324-37.

15. Mahmood F and Hansen RH. Diffusion Weighted
Magnetic Resonance Imaging for Detection of Tissue Electroporation in vivo. In: Miklavcic D, editor. Handbook of Electroporation. Springer: Cham, Switzerland, 2016.

16. van Der Toorn A, Syková E, Dijkhuizen RM, Vorísek I, Vargová L, Skobisová E, Van Lookeren Campagne M, Reese T, Nicolay K. Dynamic changes in water ADC, energy metabolism, extracellular space volume, and tortuosity in neonatal rat brain during global ischemia. Magn Reson Med 1996;36: 52-60.

17. Koh DM and Padhani AR. Diffusion-weighted MRI: a new functional clinical technique for tumour imaging. Br J Radiol 2006;79:633-5.

18. Surov A, Meyer HJ, Wienke A. Correlation between minimum apparent diffusion coefficient (ADCmin) and tumor cellularity: a meta-analysis. Anticancer Res 2017;37:3807-10.

19. Le Bihan D, Breton E, Lallemand D, Grenier P, Cabanis E, Laval-Jeantet M. MR imaging of intravoxel incoherent motions: application to diffusion and perfusion in neurologic disorders. Radiology 1986;161:401-7.

20. Som $P$ and Brandwein M. Salivary glands. In: Som PM, Curtin HD, editors. Head and neck imaging. 3rd ed. St. Louis: Mosby;1996: p. 823-914.

21. Dawes C. Circadian rhythms in human salivary flow rate and composition. J Physiol 1972;220:529-45.

22. Papagerakis S, Zheng L, Schnell S, Sartor MA, Somers E, Marder W, McAlpin B, Kim D, McHugh J, Papagerakis P. The circadian clock in oral health and diseases. J Dent Res 2014;93:27-35.

23. Cheng SCH, Wu VWC, Kwong DLW, Ying MTC. Assessment of post-radiotherapy salivary glands. Br J Radiol 2011;84:393-402.

24. Pedersen A, Sørensen CE, Proctor GB, Carpenter GH. Salivary functions in mastication, taste and textural perception, swallowing and initial digestion. Oral Dis 2018;24:1399-416.

25. Dirix P, Nuyts S, Van den Bogaert W. Radiation-induced xerostomia in patients with head and neck cancer: a literature review. Cancer 2006;107:2525-34.

26. Nagler RM. The enigmatic mechanism of irradiationinduced damage to the major salivary glands. Oral Dis 2002;8:141-6.

27. Konings AW, Coppes RP, Vissink A. On the mechanism of salivary gland radiosensitivity. Int J Radiat Oncol Biol Phys 2005;62:1187-94.

28. Robar JL, Day A, Clancey J, Kelly R, Yewondwossen M, Hollenhorst H, Rajaraman M, Wilke D. Spatial and dosimetric variability of organs at risk in head-and-neck 
intensity-modulated radiotherapy. Int J Radiat Oncol Biol Phys 2007;68:1121-30.

29. Eisbruch A, Kim HM, Terrell JE, Marsh LH, Dawson LA, Ship JA. Xerostomia and its predictors following parotidsparing irradiation of head-and-neck cancer. Int J Radiat Oncol Biol Phys 2001;50:695-704.

30. Li Y, Taylor JM, Ten Haken RK, Eisbruch A. The impact of dose on parotid salivary recovery in head and neck cancer patients treated with radiation therapy. Int J Radiat Oncol Biol Phys 2007;67:660-9.

31. Roesink JM, Moerland M, Battermann J, Hordijk GJ, Terhaard CH. Quantitative dose-volume response analysis of changes in parotid gland function after radiotherapy in the head-and-neck region. Int J Radiat Oncol Biol Phys 2001;51:938-46.

32. Jensen SB, Pedersen AML, Vissink A, Andersen E, Brown CG, Davies AN, et al. A systematic review of salivary gland hypofunction and xerostomia induced by cancer therapies: prevalence, severity and impact on quality of life. Support Care Cancer 2010;18:1039-60.

33. Mahmood F, Johannesen HH, Geertsen P, Opheim GF, Hansen RH. The effect of region of interest strategies on apparent diffusion coefficient assessment in patients treated with palliative radiation therapy to brain metastases. Acta Oncol 2015;54:1529-34.

34. Kato H, Kanematsu M, Mizuta K, Ito Y, Hirose Y. Carcinoma ex pleomorphic adenoma of the parotid gland: radiologic-pathologic correlation with MR imaging including diffusion-weighted imaging. AJNR Am J Neuroradiol 2008;29:865-7.

35. Wang J, Tang Z, Feng X, Zeng $W$, Tang $W$, Wu L, Jin L. Preliminary study of diffusion-weighted imaging and magnetic resonance spectroscopy imaging in Kimura disease. J Craniofac Surg 2014;25:2147-51.

36. Terra GT, Oliveira JX, Hernandez A, Lourenço SV, Arita ES, Cortes AR. Diffusion-weighted MRI for differentiation between sialadenitis and pleomorphic adenoma. Dentomaxillofac Radiol 2017;46:20160257.

37. Doornaert P, Dahele M, Ljumanovic R, de Bree R, Slotman BJ, Castelijns JA. Use of diffusion-weighted magnetic resonance imaging (DW-MRI) to investigate the effect of chemoradiotherapy on the salivary glands. Acta Oncol 2015;54:1068-71.

38. Dirix P, De Keyzer F, Vandecaveye V, Stroobants S, Hermans R, Nuyts S. Diffusion-weighted magnetic resonance imaging to evaluate major salivary gland function before and after radiotherapy. Int J Radiat Oncol Biol Phys 2008;71:1365-71.
39. Thoeny HC, De Keyzer F, Claus FG, Sunaert S, Hermans R. Gustatory stimulation changes the apparent diffusion coefficient of salivary glands: initial experience. Radiology 2005;235:629-34.

40. Liu YJ, Lee YH, Chang HC, Huang TY, Chiu HC, Wang CW, Chiou TW, Hsu K, Juan CJ, Huang GS, Hsu HH. A potential risk of overestimating apparent diffusion coefficient in parotid glands. PLoS One 2015;10:e0124118.

41. Zhou N, Chu C, Dou X, Li M, Liu S, Zhu L, Liu B, Guo T, Chen W, He J, Yan J, Zhou Z, Yang X, Liu T. Early evaluation of irradiated parotid glands with intravoxel incoherent motion MR imaging: correlation with dynamic contrast-enhanced MR imaging. BMC Cancer 2016;16:865.

42. Kato H, Kanematsu M, Toida M, Kawaguchi T, Shibata T, Kajita K, Hoshi H. Salivary gland function evaluated by diffusion-weighted MR imaging with gustatory stimulation: preliminary results. J Magn Reson Imaging 2011;34:904-9.

43. Habermann CR, Gossrau P, Kooijman H, Graessner J, Cramer MC, Kaul MG, Reitmeier F, Jaehne M, Adam G. Monitoring of gustatory stimulation of salivary glands by diffusion-weighted MR imaging: comparison of $1.5 \mathrm{~T}$ and 3T. AJNR Am J Neuroradiol 2007;28:1547-51.

44. Zhang Y, Ou D, Gu Y, He X, Peng W, Mao J, Yue L, Shen $\mathrm{X}$. Diffusion-weighted MR imaging of salivary glands with gustatory stimulation: comparison before and after radiotherapy. Acta Radiol 2013;54:928-33.

45. Zhou N, Guo T, Zheng H, Pan X, Chu C, Dou X, Li M, Liu S, Zhu L, Liu B, Chen W, He J, Yan J, Zhou Z, Yang $\mathrm{X}$. Apparent diffusion coefficient histogram analysis can evaluate radiation-induced parotid damage and predict late xerostomia degree in nasopharyngeal carcinoma. Oncotarget 2017;8:70226-38.

46. Yoshino N, Yamada I, Ohbayashi N, Honda E, Ida M, Kurabayashi T, Maruyama K, Sasaki T. Salivary glands and lesions: evaluation of apparent diffusion coefficients with split-echo diffusion-weighted MR imaging-initial results. Radiology 2001;221:837-42.

47. Sumi M, Van Cauteren M, Sumi T, Obara M, Ichikawa Y, Nakamura T. Salivary gland tumors: use of intravoxel incoherent motion MR imaging for assessment of diffusion and perfusion for the differentiation of benign from malignant tumors. Radiology 2012;263:770-7.

48. Zhou N, Chen W, Pan X, He J, Yan J, Zhou Z, Yang X. Early evaluation of radiation-induced parotid damage with diffusion kurtosis imaging: a preliminary study. Acta Radiol 2018;59:212-20. 
49. Matsushima N, Maeda M, Takamura M, Takeda K. Apparent diffusion coefficients of benign and malignant salivary gland tumors. Comparison to histopathological findings. J Neuroradiol 2007;34:183-9.

50. Juan CJ, Chang HC, Hsueh CJ, Liu HS, Huang YC, Chung HW, Chen CY, Kao HW, Huang GS. Salivary glands: echo-planar versus PROPELLER Diffusionweighted MR imaging for assessment of ADCs. Radiology 2009;253:144-52.

51. Marzi S, Forina C, Marucci L, Giovinazzo G, Giordano C, Piludu F, Landoni V, Spriano G, Vidiri A. Early radiationinduced changes evaluated by intravoxel incoherent motion in the major salivary glands. J Magn Reson Imaging 2015;41:974-82.

52. Zhang W, Zuo Z, Huang X, Jin G, Su D. Value of diffusion-weighted imaging combined with susceptibilityweighted imaging in differentiating benign from malignant parotid gland lesions. Med Sci Monit 2018;24:4610-6.

53. Matsusue E, Fujihara Y, Matsuda E, Tokuyasu Y, Nakamoto S, Nakamura K, Ogawa T. Differentiating parotid tumors by quantitative signal intensity evaluation on MR imaging. Clin Imaging 2017;46:37-43.

54. Ikeda M, Motoori K, Hanazawa T, Nagai Y, Yamamoto S, Ueda T, Funatsu H, Ito H. Warthin tumor of the parotid gland: diagnostic value of MR imaging with histopathologic correlation. AJNR Am J Neuroradiol 2004;25:1256-62.

55. Fruehwald-Pallamar J, Czerny C, Holzer-Fruehwald L, Nemec SF, Mueller-Mang C, Weber M, Mayerhoefer ME. Texture-based and diffusion-weighted discrimination of parotid gland lesions on MR images at 3.0 Tesla. NMR Biomed 2013;26:1372-9.

56. Eida S, Sumi M, Sakihama N, Takahashi H, Nakamura T. Apparent diffusion coefficient mapping of salivary gland tumors: prediction of the benignancy and malignancy. AJNR Am J Neuroradiol 2007;28:116-21.

57. Kato H, Fujimoto K, Matsuo M, Mizuta K, Aoki M. Usefulness of diffusion-weighted MR imaging for differentiating between Warthin's tumor and oncocytoma of the parotid gland. Jpn J Radiol 2017;35:78-85.

58. Milad P, Elbegiermy M, Shokry T, Mahmoud H, Kamal I, Taha MS, Keriakos N. The added value of pretreatment DW MRI in characterization of salivary glands pathologies. Am J Otolaryngol 2017;38:13-20.

59. Motoori K, Yamamoto S, Ueda T, Nakano K, Muto T, Nagai Y, Ikeda M, Funatsu H, Ito H. Inter- and intratumoral variability in magnetic resonance imaging of pleomorphic adenoma: an attempt to interpret the variable magnetic resonance findings. J Comput Assist Tomogr 2004;28:233-46.

60. Yabuuchi H, Matsuo Y, Kamitani T, Setoguchi T, Okafuji T, Soeda H, Sakai S, Hatakenaka M, Nakashima T, Oda Y, Honda H. Parotid gland tumors: can addition of diffusionweighted MR imaging to dynamic contrast-enhanced MR imaging improve diagnostic accuracy in characterization? Radiology 2008;249:909-16.

61. Zhang W, Zuo Z, Luo N, Liu L, Jin G, Liu J, Su D. Nonenhanced MRI in combination with color Doppler flow imaging for improving diagnostic accuracy of parotid gland lesions. Eur Arch Otorhinolaryngol 2018;275:987-95.

62. Sumi M, Takagi Y, Uetani M, Morikawa M, Hayashi K, Kabasawa H, Aikawa K, Nakamura T. Diffusion-weighted echoplanar MR imaging of the salivary glands. AJR Am J Roentgenol 2002;178:959-65.

63. Ma G, Zhu LN, Su GY, Hu H, Qian W, Bu SS, Xu $\mathrm{XQ}, \mathrm{Wu} \mathrm{FY}$. Histogram analysis of apparent diffusion coefficient maps for differentiating malignant from benign parotid gland tumors. Eur Arch Otorhinolaryngol 2018;275:2151-7.

64. Regier M, Ries T, Arndt C, Cramer MC, Graessner J, Reitmeier F, Jaehne M, Adam G, Habermann CR. Sjögren's syndrome of the parotid gland: value of diffusionweighted echo-planar MRI for diagnosis at an early stage based on MR sialography grading in comparison with healthy volunteers. Rofo 2009;181:242-8.

65. Sun Q, Ma C, Dong M, Jiang M, Tao X. Effects of region of interest sizes on apparent diffusion coefficient measurements of pleomorphic adenoma, Warthin tumor, and normal parotid parenchyma. Quant Imaging Med Surg 2019;9:681-90.

66. Ries T, Arndt C, Regier M, Graessner J, Cramer MC, Reitmeier F, Jaehne M, Adam G, Habermann CR. Value of apparent diffusion coefficient calculation before and after gustatory stimulation in the diagnosis of acute or chronic parotitis. Eur Radiol 2008;18:2251-7.

67. Celebi I, Mahmutoglu AS, Ucgul A, Ulusay SM, Basak T, Basak M. Quantitative diffusion-weighted magnetic resonance imaging in the evaluation of parotid gland masses: a study with histopathological correlation. Clin Imaging 2013;37:232-8.

68. Wang J, Takashima S, Takayama F, Kawakami S, Saito A, Matsushita T, Momose M, Ishiyama T. Head and neck lesions: characterization with diffusion-weighted echoplanar MR imaging. Radiology 2001;220:621-30.

69. Chang HC, Juan CJ, Chiu HC, Cheng CC, Chiu SC, Liu YJ, Chung HW, Hsu HH. Effects of gender, age, and 
body mass index on fat contents and apparent diffusion coefficients in healthy parotid glands: an MRI evaluation. Eur Radiol 2014;24:2069-76.

70. Habermann CR, Arndt C, Graessner J, Diestel L, Petersen KU, Reitmeier F, Ussmueller JO, Adam G, Jaehne M. Diffusion-weighted echo-planar MR imaging of primary parotid gland tumors: is a prediction of different histologic subtypes possible? AJNR Am J Neuroradiol 2009;30:591-6.

71. Gudbjartsson H and Patz S. The Rician distribution of noisy MRI data. Magn Reson Med 1995;34:910-4.

72. Jones DK. Diffusion MRI: Theory, methods, and applications. Oxford University Press, Inc: New York; 2011.

73. Mahmood F, Johannesen HH, Geertsen P, Hansen RH. Ultra-early apparent diffusion coefficient change indicates irradiation and predicts radiotherapy outcome in brain metastases. Acta Oncol 2017;56:1651-3.

74. Coppes RP, Zeilstra LJ, Kampinga HH and Konings AW. Early to late sparing of radiation damage to the parotid gland by adrenergic and muscarinic receptor agonists. $\mathrm{Br} \mathrm{J}$ Cancer 2001;85:1055-63.

75. Dawes C. Physiological factors affecting salivary flow rate, oral sugar clearance, and the sensation of dry mouth in man. J Dent Res 1987;66:648-53.

Cite this article as: Bruvo M, Mahmood F. Apparent diffusion coefficient measurement of the parotid gland parenchyma. Quant Imaging Med Surg 2021;11(8):3812-3829. doi: 10.21037/ qims-20-1178
76. Chang HC, Juan CJ, Chiu HC, Cheng CC, Chiu SC, Liu YJ, Chung HW, Hsu HH. Effects of gender, age, and body mass index on fat contents and apparent diffusion coefficients in healthy parotid glands: an MRI evaluation. Eur Radiol 2014;24:2069-76.

77. Dawes C. Effects of diet on salivary secretion and composition. J Dent Res 1970;49:1263-73.

78. Navazesh M, Brightman VJ, Pogoda JM. Relationship of medical status, medications, and salivary flow rates in adults of different ages. Oral Surg Oral Med Oral Pathol Oral Radiol Endod 1996;81:172-6.

79. Bruvo M, Moe D, Kirkeby S, Vorum H, Bardow A. Individual variations in protective effects of experimentally formed salivary pellicles. Caries Res 2009;43:163-70.

80. Foglio-Bonda PL, Migliario M, Rocchetti V, Pattarino F, Foglio-Bonda A. Daily and annually variation of unstimulated whole saliva flow rate and $\mathrm{pH}$ and their relation with body profile in healthy young adults. Eur Rev Med Pharmacol Sci 2013;17:2538-45.

81. Roesink JM and Terhaard CHJ. The influence of clinical factors on human stimulated parotid flow rate in cancer and other patients. Oral Oncol 2002;38:291-5. 